\title{
Formulasi Strategi Bisnis PT Jalan Tol Perkasa
}

\author{
Reza Febriano \\ Program Studi Magister Manajemen Eksekutif, Sekolah Tinggi Manajemen PPM \\ Jl. Menteng Raya No.9, Kb. Sirih, Kec. Menteng, Kota Jakarta Pusat, Jakarta, Indonesia \\ rezafebriano@gmail.com
}

\section{Ningky Sasanti Munir*}

Program Studi Magister Manajemen Eksekutif, Sekolah Tinggi Manajemen PPM

Jl. Menteng Raya No.9, Kb. Sirih, Kec. Menteng, Kota Jakarta Pusat, Jakarta, Indonesia ningkymunir@gmail.com

Diterima: 09-02-2021

Disetujui: 16-06-2021

Dipublikasi: 30-06-2021

\begin{abstract}
ABSTRAK
PT Jalan Tol Perkasa (PT JTP) merupakan salah satu unit stratejik kelompok bisnis PT. Jasa Marga (Persero), Tbk. (JSMR) yang beroperasi di bidang pengembangan dan pemeliharaan jalan tol. Dengan adanya pandemi Covid19, JTP perlu merumuskan strategi bisnis yang sesuai agar dapat diimplementasikan untuk dapat mencapai target pendapatan usaha dan laba periode 2020-2022. Penelitian ini merupakan penelitian terapan yang menggunakan kerangka kerja penyusunan strategi bisnis dari David \& David (2016). Melalui kerangka kerja tersebut, kualitas respons stratejik JTP terhadap potensi peluang dan ancaman dari lingkungan eksternal dievaluasi melalui matriks External Factors Evaluation (EFE), sementara kekuatan dan kelemahan JTP dievaluasi melalui matriks Internal Factors Evaluation (IFE). Pengembangan alternatif strategi dilakukan dengan menggunakan dua matriks: matriks internal-eksternal (IE) dan matriks SWOT (Strength, Weakness, Opportunity, Threat). Dari matriks IE, diketahui bahwa JTP berada pada posisi tahan dan pelihara, dimana alternatif strategi bisnis yang sebaiknya diambil adalah penetrasi pasar dan pengembangan produk. Dari matriks SWOT dihasilkan tiga strategi yang dapat diimplementasikan yaitu, mendapatkan pekerjaan pemeliharaan di seluruh ruas jalan tol Jasa Marga Group dam Non Jasa Marga, penerapan Performance Based Maintenance Contract (PBMC) dengan kontrak jangka panjang, dan melakukan inovasi produk-produk pemeliharaan. Terakhir, strategi prioritas yang akan segera dilaksanakan ditentukan dengan menggunakan matriks Quantitave Strategic Planning Matrix (QSPM)
\end{abstract}

Kata Kunci:

Strategi Bisnis; Tahan dan Pelihara;Penetrasi Pasar;Pengembangan Produk;Pemeliharaan Jalan Tol.

\begin{abstract}
PT Jalan Tol Perkasa (PT JTP) is one of the strategic units of the PT. Jasa Marga (Persero), Tbk. (JSMR) which operates in the field of toll road development and maintenance. With the Covid19 pandemic, JTP needs to formulate the appropriate business strategy so that it can be implemented in order to achieve the business revenue and profit targets for the 2020-2022 period. This research is an applied research that uses a business strategy formulation framework from David \& David (2016). Through this framework, the quality of JTP's strategic response to potential opportunities and threats from the external environment is evaluated through the External Factors Evaluation (EFE) matrix, while JTP's strengths and weaknesses are evaluated through the Internal Factors Evaluation (IFE) matrix. The development of alternative strategies is carried out using two matrices: an internal-external matrix (IE) and a SWOT matrix (Strength, Weakness, Opportunity, Threat). From the IE matrix, it is known that JTP is in a position to hold and maintain, where the alternative business strategies that should be taken are market penetration and product development. From the SWOT matrix, three strategies can be implemented: obtaining maintenance work on all Jasa Marga Group and Non Jasa Marga toll roads, implementing Performance Based Maintenance Contracts (PBMC) with long-term contracts, and innovating maintenance products. Finally, the priority strategy that will soon be implemented is determined using the Quantitative Strategic Planning Matrix (QSPM) matrix.
\end{abstract}

Keywords:

Business Strategy; Hold and Maintain; Market Penetration; Product Development; Toll-Road Maintenance 


\section{PENDAHULUAN}

PT Jalan Tol Perkasa (PT JTP; bukan nama sebenarnya) adalah salah satu entitas anak perusahaan dari PT Jasa Marga (Persero) Tbk. (Jasa Marga). Sebelumnya, JTP bernama PT Jasa Layanan Pemeliharaan (JLP), yang diakuisisi oleh Jasa Marga tahun tahun 2010. Pada tahun 2017, Jasa Marga melakukan transformasi internal dengan melakukan perubahan di dalam organisasi perusahaan dengan membagi peran dan fungsi Kantor Pusat sebagai Asset Owner, Regional/Cabang sebagai Asset Manager, dan Anak Perusahaan Usaha Lain seperti JTP sebagai Service Provider. Tujuan pembagian peran dan fungsi tersebut adalah untuk mensinergikan dan mengembangkan aset-aset yang dimiliki oleh perusahaan.

Pada tahun 2018 Jasa Marga selaku induk perusahaan mengarahkan JTP sebagai salah satu entitas anak perseroaan di bidang jasa layanan pemeliharaan, sebagai pemelihara aset dalam rantai nilai bisnis jalan tol. Jasa Marga mengalihkan pengelolaan pekerjaan pemeliharaan yang sebelumnya dilakukan oleh cabang dan pihak-pihak ketiga menjadi ke JTP. Hal tersebut dilakukan dengan maksud untuk meningkatkan kapasitas dan daya saing JTP agar fokus di bidang jasa layanan pemeliharaan dalam rangka pemenuhan Standar Pelayanan Minimal (SPM) jalan tol.

Sejalan dengan proses transformasi Jasa Marga, ruang lingkup bisnis JTP berubah dari kontraktor menjadi dikembangkan pada tiga lini bisnis yang terdiri dari:

1. Manajemen Pemeliharaan Jalan Tol melalui Kontrak Manajemen di Grup Jasa Marga, meliputi kegiatan perencanaan dan pelaksanaan pemeliharaan jalan tol termasuk Regional/Cabang/Anak Perusahaan Jalan Tol.

2. Pekerjaan Pemeliharaan di luar Grup Jasa Marga, meliputi pelaksanaan pemeliharaan periodik, peningkatan kapasitas jalan tol dan pemeliharaan rutin jalan tol di luar Grup Jasa Marga dan Jalan Nasional.

3. Asphalt Mixing Plant (AMP) Retail \& Heavy Equipment (HE) Rental, meliputi penyediaan campuran aspal melalui AMP serta penggunaan dan penyewaan alat berat.

Konsekuensi pelaksanaan Kontrak Manajemen Pemeliharaan di atas menyebabkan JTP tidak bisa lagi memposisikan diri sebagai kontraktor untuk pekerjaan yang berada di Grup Jasa Marga. Hal tersebut mengakibatkan sumber daya manusia yang berada di Bagian Produksi AMP dan peralatan berat untuk penghampar aspal sementara waktu berhenti beroperasi. Kondisi ini memerlukan penanganan agar JTP tidak kehilangan sumber daya manusia yang memiliki keahlian dalam bidang konstruksi, serta menanggung beban amortisasi dan depresiasi alat-alat berat yang setiap tahun diperhitungkan.

Sesuai dengan arahan dari perusahaan induk, JTP telah menetapkan target pendapatan usaha pada tahun 2020 sebesar Rp. 2,02 Triliun dengan target laba sebesar Rp. 104,61 Milyar; target pendapatan usaha pada tahun 2021 sebesar Rp. 2,14 Triliun dengan target laba 114,49 Miliar; serta target pendapatan usaha pada tahun 2022 sebesar Rp. 2,28 Triliun dengan target laba 125,17 Miliar. Untuk itu, JTP perlu merumuskan strategi bisnis yang sesuai agar dapat mencapai target pendapatan 
usaha dan laba untuk periode 2020 sampai dengan 2022. Selain upaya untuk mencapai target pendapatan usaha dan laba, rumusan strategi bisnis juga ditujukan untuk mengatasi kemungkinan dampak pandemi pada perusahaan.

Berdasarkan latar belakang di atas, tujuan penelitian ini adalah merumuskan Strategi Bisnis PT Jalan Tol Perkasa (PT JTP) Periode Tahun 2020-2022. Secara rinci, penelitian ini bertujuan untuk mengidentifikasikan isu stratejik eksternal dan internal yang dihadapi oleh PT JTP dalam bentuk peluang, ancaman, kekuatan, dan kelemahan; mengembangkan alternatif strategi bisnis; dan menetapkan prioritas strategi bisnis. Tahun 2020-2022.

\section{Analisis visi perusahaan}

Visi dapat diartikan sebagai pernyataan berbentuk sebuah pedoman yang tidak spesifik dan dapat menjawab pertanyaan seperti "what do we want to become?" dalam suatu organisasi atau perusahaan (Collis \& Porras, 2005). Dalam konteks perumusan strategi bisnis sebuah pernyataan visi dapat menunjukkan ke arah mana perusahaan tersebut akan melangkah (Collis \& Porras, 2005; Slintak, \& Dvorsky, 2019). Selain itu, seperti dalam penelitian yang dilakukan oleh Gulati dkk. (2016) di industri rumah sakit di Amerika Serikat, sebuah pernyataan visi juga mencerminkan sebuah target atau kondisi ideal yang hendaknya ingin dicapai oleh suatu organisasi atau perusahaan dalam konteks jangka waktu yang panjang. Oleh sebab itu penelitian ini dimulai dengan analisis visi perusahaan yang menjadi acuan perumusan strategi bisnis.

\section{Analisis lingkungan eksternal}

David \& David (2016) menjelaskan bahwa tujuan dari analisis eksternal adalah untuk mengembangkan daftar peluang yang terbatas yang dapat menguntungkan perusahaan dan ancaman yang harus dihindari. Serfointein \& Govender (2020) menyatakan bahwa lingkungan eksternal (yang mencakup industri di mana perusahaan bersaing) memengaruhi respons yang diambil perusahaan untuk mengungguli pesaing dan mendapatkan pengembalian di atas rata-rata. Dari kedua pendapat tersebut dapat disimpulkan bahwa kegunaaan analisis eksternal yaitu untuk mengidentifikasi kesempatankesempatan dan ancaman-ancaman yang sedang atau mungkin akan terjadi pada waktu beberapa tahun ke depan yang dapat mempengaruhi kinerja organisasi atau perusahaan dalam mencapai target atau tujuan organisasi atau perusahaan tersebut. Analisis eksternal juga menghasilkan suatu kajian terkait kemampuan organisasi atau perusahaan dalam memanfaatkan kesempatan-kesempatan serta melakukan mitigasi atas ancaman yang teridentifikasi dalam rangka mengungguli kompetitor dan mencapai tingkat pengembalian yang terbaik (Karsaman, \& Weningtyas, 2015, Singh \& Srivastava, 2019, Serfointein \& Govender, 2020).

Pada umumnya dalam suatu organisasi atau perusahaan, analisis eksternal dibagi dalam dua kategori besar yaitu analisis secara makro dan analisis industri di mana organisasi atau perusahaan itu berada. (David \& David, 2016). Adapun pendekatan yang digunakan sebagai rujukan dalam penelitian ini adalah analisis PESTEL (Political, Economic, Socio-cultural, Technological, Environment \& Legal) 
untuk mengidentifikasi potensi peluang dan ancaman dari lingkungan makro (Singh \& Srivastava, 2019, Serfointein \& Govender, 2020). Untuk melakukan analisis lingkungan eksternal yang lebih rinci, David \& David (2016) menyarankan penggunakan analisis lima kekuatan bersaing dari Porter (1980), yang terdiri dari Tekanan Pendatang Baru (Threat of New Entrants), Tekanan Intensitas Persaingan (Competitive Rivalry), Tekanan Produk Pengganti (Threat of Substitute), Tekanan Daya Tawar Pemasok (Bargaining Power of Suppliers), dan Tekanan Daya Tawar Pembeli (Bargaining Power of Buyers).

Menurut David \& David (2016), hasil analisis lingkungan eksternal, baik lingkungan makro maupu industri kemudian dikompilasikan dalam suatu matriks yang disebut matriks External Factors Evaluation (EFE). Matriks EFE menunjukkan hubungan antara seberapa signifikan pengaruhi peluang dan ancaman dari lingkungan eksternal pada industri dimana perusahaan berada, dan kualitas respons stratejik perusahaan dalam menanggapinya.

\section{Analisis Lingkungan Internal}

David \& David (2016) menjelaskan bahwa semua organisasi memiliki kekuatan dan kelemahan di bidang fungsional bisnis. Tidak ada perusahaan yang sama kuat atau lemahnya di semua bidang. Kekuatan dan kelemahan internal, ditambah dengan potensi peluang dan ancaman eksternal serta pernyataan visi yang jelas, akan memberikan dasar untuk merumuskan strategi bisnis. Menurut David \& David (2016) analisis internal adalah analisis yang dilakukan terhadap kekuatan serta kelemahan sebuah perusahaan atau organisasi. Kekuatan berarti kondisi di mana sebuah perusahaan dapat memanfaatkan serta dapat memenuhi target pasar sedangkan kelemahan adalah kondisi di mana perusahaan mengalami keterbatasan dalam memenuhi target pasar.

Salah satu pendekatan untuk mengidentifikasikan kekuatan dan kelemahan perusahaan adalah analisis rantai nilai atau Value Chain Analysis yang dikembangkan oleh Porter (1998). Analisis Rantai Nilai adalah suatu alat analisis yang digunakan untuk memahami keunggulan perusahaan. Spesifiknya adalah untuk mengidentifikasi dimana nilai bagi pelanggan dapat ditingkatkan atau dimana biaya dapat diturunkan (Porter, 1998). Rantai nilai ini mengidentifikasikan dan menghubungkan berbagai aktivitas strategik suatu perusahaan. Sifat rantai nilai tergantung pada sifat industri dan bisa berbeda-beda untuk satu perusahaan dengan perusahaan lainnya.

Menurut David \& David (2016), hasil analisis lingkungan internal kemudian dikompilasikan dalam suatu matriks yang disebut matriks Internall Factors Evaluation (IFE). Matriks IFE menunjukkan faktor-faktor internal yang menjadi kekuatan mayor dan minor, serta kelemahan mayor dan minor perusahaan.

\section{Pengembangan Alternatif Strategi}

Kualitas respons stratejik perusahaan, kondisi eksternal dimana perusahaan beroperasi, serta kekuatan dan kelemahan internal yang dimiliki membuat alternatif strategi bisnis perusahaan berbeda satu dengan yang lain. Menurut David \& David (2016) alat analisis yang dapat membantu eksekutif 
mengembangkan alternatif stratejik adalah matriks IE (Internal-External). Dalam matriks tersebut, perusahaan dapat berada pada posisi build and growth, hold and maintain, atau harvest and divest. Perusahaan yang berada pada posisi build and growth dan mengembangkan strategi bisnis yang agresif dengan melakukan integrasi vertikal, intergrasi horisontal, dan intensif seperti penetrasi pasar, pengembangan produk, pengembangan pasar, serta diversifikasi bisnis. Namun perusahaan yang berada pada posisi hold and maintain sebaik mengembangkan strategi bisnis intensif, yaitu penetrasi pasar, dan pengembangan produk.

Untuk mendetilkan strategi bisnis perusahaan, David \& David (2016) menyarankan untuk menggunakan analisis SWOT (Strength, Weaknesses, Opportunity, Threat) dan membuat matriks TOWS untuk mengembangkan alternatif strategi. Walau tampak sudah umum, namun menurut Coman \& Ronen, (2009), Helms \& Nixon (2010) serta penelitian yang lebih terkini dari Vlados (2019), analisis SWOT merupakan analisis yang secara efektif dapat membantu eksekutif meneliti faktor-faktor stratejik dari lingkungan eksternal dimana perusahaan berada, dan memadukannya dengan kekuatankekuatan yang dimiliki untuk mengembangkan alternatif strategi. Vlados (2019) juga menekankan peras analisis SWOT dalam membantu perusahaan memanfaatkan faktor-faktor eksternal untuk mengatasi keleMahan-kelemahan yang dimiliki.

\section{Penetapan Strategi Prioritas}

Menurut David \& David (2016) karena keterbatasan waktu, kemungkinan pula dana, dan urgensi dari permasalahan yang dihadapi, maka perusahan perlu menetapkan strategi prioritas yang akan segera diterapkan. David \& David (2016) mengembangkan alat analisis Quantitative Strategic Priority Matrix (QSPM) yaitu alat analisis yang memungkinkan para pengambil keputusan untuk mengevaluasi strategi alternatif secara objektif, berdasarkan pada faktor-faktor kunci baik dari lingkungan eksternal (matriks EFE) maupun internal (matriks IFE) yang telah diidentifikasi sebelumnya. Secara konseptual QSPM adalah teknik dan metode yang sangat umum dalam evaluasi opsi strategis dan penentuan daya tarik relatif strategi; daya tarik strategi digunakan dalam tahap pengambilan keputusan Pazouki, dkk (2017). Teknik ini menentukan mana dari opsi strategis yang dipilih yang layak, dan itu sebenarnya memprioritaskan strategi ini (Abbasi, dkk., 2019).

\section{Kerangka Analisis}

Kerangka analisis berisi langkah-langkah yang akan dilakukan dalam kegiatan penelitian ini untuk mencapai tujuan penelitian. Kerangka analisis yang digambarkan pada Gambar 1 akan menjadi acuan dalam melakukan penelitian yang dimulai dari analisis visi perusahaan, dilanjutkan dengan analisis lingkungan eksternal dengan menggunakan analisis PESTLE dan analisis industri yang hasilnya dikompilasi dalam matriks EFE.

Selanjutnya dilakukan analisis internal dengan menggunakan pendekatan analisis rantai nilai yang hasilnya dikompilasi dalam matriks IFE. Pengembangan alternatif strategi dilakukan dengan menggunakan dua alat analisis, yaitu matriks IE dan matriks TOWS. Dengan merujuk pada visi dan 
sasaran stratejik perusahaan, dikembangkan alternatif strategi yang ditentukan prioritasnya dengan menggunakan QSPM

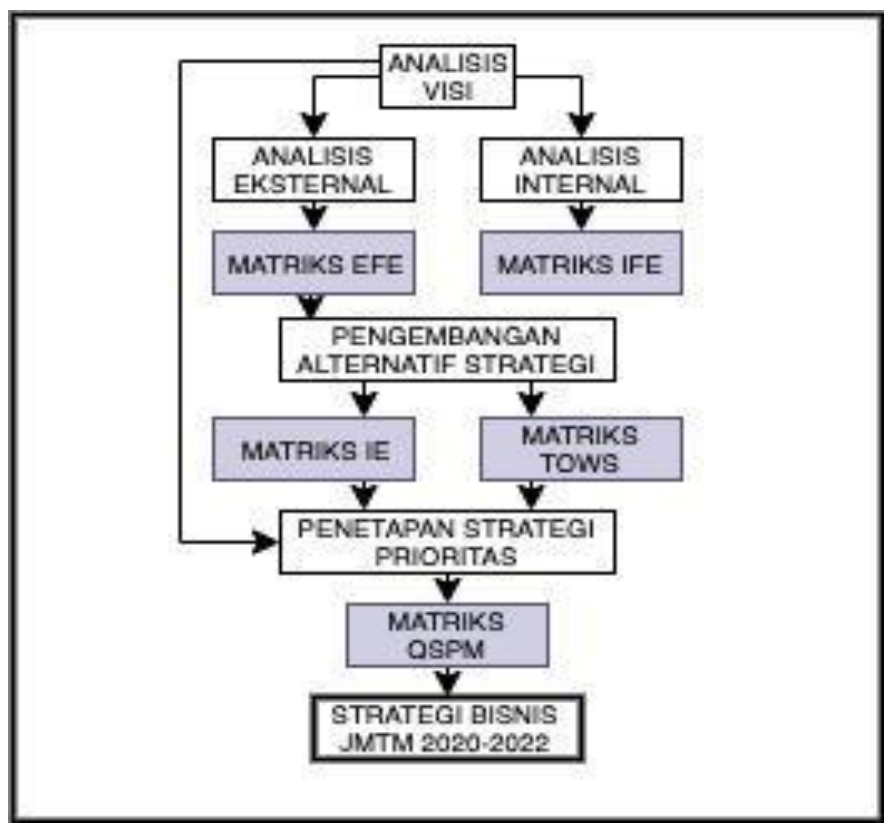

\section{Gambar 1. Kerangka Analisis Perumusan Strategi Bisnis} Sumber : Hasil pengolahan penulis

\section{METODE RISET}

Jenis penelitian yang dilakukan oleh penulis pada penelitian ini adalah kualitatif. Penelitian kualitatif adalah suatu penelitian yang ditujukan untuk mendeskripsikan dan menganalisis fenomena, peristiwa, aktivitas sosial, sikap, kepercayaan, persepsi, pemikiran orang secara individual maupun kelompok (Denzin \& Lincoln, 2018). Penelitian kualitatif bersifat induktif, peneliti membiarkan permasalahan-permasalahan muncul dari data atau dibiarkan terbuka untuk interpretasi. Data yang dihimpun dengan pengamatan yang seksama, mencakup deskripsi dalam konteks yang mendetail disertai catatan-catatan hasil wawancara yang mendalam, serta hasil analisis dokumen dan catatancatatan (Denzin \& Lincoln, 2018).

Penelitian dilakukan pada salah satu anak perusahaan Jasa Marga yang bergerak dalam bisnis pemeliharaan jalan tol yaitu JTP yang berlokasi di Plaza Tol Jagorawi, Jalan Raya Taman Mini Indonesia Indah, Jakarta Timur. Sumber data primer pada penelitian ini diperoleh langsung dari hasil wawancara narasumber kunci yaitu para Direksi PT Jalan Tol Perkasa (PT JTP), Direktur Bisnis PT Jasa Marga (Persero) Tbk. (Jasa Marga), dan unsur dari Badan Pengatur Jalan Tol (BPJT). Protokol wawancara dikembangkan melalui kajian teori, khususnya mengenai analisis visi perusahaan, analisis eksternal dan internal, dan pengembangan alternatif strategi bisnis.

Pada penelitan ini, data sekunder diperoleh dari dokumen perusahaan milik JTP. Dokumen tersebut antara lain Rencana Jangka Panjang Perusahaan (RJPP) Periode 2019 sampai dengan 2029, Laporan Keuangan periode tahun 2013 sampai dengan 2019, dan Rencana Keuangan Anggaran 
Perusahaan (RKAP) Tahun 2020, serta referensi lainnya yang digunakan untuk melengkapi analisis eksternal bersumber dari buku, artikel dari intenet dan jurnal/penelitian ilmiah yang berkaitan dengan perumusan strategi bisnis. Data dan informasi hasil wawancara dan hasil telaah dokumen-dokumen kemudian disusun dan dipilah ke dalam jenis analisis yang telah distrukturkan dalam kerangka analisis.

\section{HASIL PENELITIAN DAN PEMBAHASAN}

\section{Analisis visi perusahaan.}

Adapun visi JTP adalah "Menjadi kontraktor pemeliharaan jalan tol yang profesional, terpercaya, dan terkemuka." Tiga kata kunci yang menjadi acuan dalam visi JTP adalah: profesional, terpercaya, dan terkemuka. Pada saat ini JTP masih dalam proses untuk mewujudkan secara konsisten pengerjan proyek yang tepat mutu, tepat biaya, peduli terhadap keselamatan dan lingkungan. Masih adanya beberapa proyek peningkatan kapasitas dan pekerjaan pemeliharaan rutin yang terlambat, serta hasil pekerjaan yang kurang memenuhi spesifikasi.

Untuk mengembangkan profesionalisme baik SDM dan organisasi merupakan tantangan tersendiri bagi JTP. Kondisi saat ini personil yang ditugaskan untuk menduduki jabatan struktural didominasi oleh karyawan Jasa Marga yang ditugaskan ke JTP, sedangkan karyawan yang ditugaskan di lapangan merupakan hasil perekrutan internal JTP. Perubahan organisasi JTP dilakukan secara dinamis yang disesuaikan dengan tuntutan strategi perusahaan dan pengisian formasi jabatan didasarkan pada kompetensi yang diperlukan.

JTP berusaha menjadi perusahaan yang profesional, terpercaya, dan terkemuka antara lain dengan mewujudkan Sistem Manajemen Pemeliharaan Jalan Tol saat ini masih terus dikembangkan. Sistem Manajemen Pemeliharaan Jalan Tol merupakan komponen stratejik untuk menjamin ketercapaian visi JTP untuk melaksanakan kegiatan pemeliharaan mulai dari hulu sampai hilir, dan tidak hanya digunakan pada ruas-ruas Jasa Marga Grup saja, namun dapat menjadi peluang ditawarkan pada ruas-ruas jalan tol di luar Jasa Marga Grup.

\section{Analisis lingkungan eksternal}

Merujuk pada visi JTP, industri dimana JTP beroperasi adalah industri kontraktor pemeliharaan jalan tol. Analisis PESTLE memberikan enam peluang dan satu ancaman, sementara analisis industri menghasilkan dua peluang dan enam ancaman. Ancaman terutama datang dari industri kontraktor pemeliharaan jalan tol yang daya tariknya rendah akibat tekanan daya tawar pembeli dan tekanan persaingan dalam industri. Potensi peluang dan potensi ancaman kemudian dikompilasi dalam matriks EFE (Tabel 1). Nilai tertimbang 2,78, atau di atas rata-rata 2,5 dari matriks EFE menunjukkan bahwa kualitas respons stratejik JTP untuk menangkap peluang dan mengatasi ancaman masih cukup baik 
Tabel 1. Matrik EFE

\begin{tabular}{clccc}
\hline No & \multicolumn{1}{c}{ Peluang } & Bobot & Rating & Score \\
\hline 1 & Masifnya Target Pembangunan Infrastruktur Jalan Tol hingga 2024 & 0,04 & 2 & 0,09 \\
2 & Proyeksi Pertumbuhan Ekonomi Indonesia yang Relatif Tinggi & 0,05 & 2 & 0,10 \\
3 & Peningkatan Jumlah Kendaraan Bermotor & 0,07 & 3 & 0,20 \\
4 & Pemeliharaan Preventif Jalan & 0,07 & 4 & 0,25 \\
5 & Implementasi Green Construction & 0,04 & 2 & 0,08 \\
6 & Pemenuhan Regulasi Standar Pelayanan Minimal Jalan Tol & 0,10 & 4 & 0,35 \\
7 & Pelaksanaan Kontrak Manajemen Pemeliharaan & 0,09 & 4 & 0,33 \\
8 & Menjalankan Etika Bisnis & 0,09 & 3 & 0,31 \\
\hline No & \multicolumn{1}{c}{ Ancaman } & Bobot & Rating & Score \\
\hline 1 & Regulasi yang ketat terkait Undang-Undang Jasa Konstruksi & 0,06 & 2 & 0,14 \\
2 & Tuntutan Stakeholder yang Tinggi cont: Pemerintah, Pengguna Jalan Tol & 0,07 & 3 & 0,18 \\
3 & Keterbatasan jumlah supplier untuk produk/jasa pekerjaan pemeliharaan & 0,04 & 3 & 0,11 \\
& yang bersifat khusus dan spesifik & & & \\
4 & Kompetisi melalui tender yang semakin ketat & 0,07 & 2 & 0,17 \\
5 & Pesaing semakin banyak karena industri pemeliharaan jalan tol mudah & 0,08 & 2 & 0,17 \\
& diduplikasi model bisnisnya & 0,06 & 2 & 0,12 \\
6 & Produk-produk penganti yang dipatenkan oleh Kompetitor & 0,06 & 3 & 0,18 \\
7 & Kompetitor menyediakan layanan Kontrak Manajemen Pemeliharaan lebih & & & \\
& baik $\quad$ TOTAL & 1,00 & & 2,78 \\
\hline & $\quad$ Tumber : David \& David (2016) ; hasil pengolahan penulis & &
\end{tabular}

\section{Analisis Internal}

Identifikasi kekuatan dan kelemahan dilakukan dengan menggunakan analisis rantai nilai. Terdapat tiga aktivitas yang dilakukan dalam pendekatan rantai nilai ini. Aktivitas pertama atau aktivitas pokok merupakan kegiatan-kegiatan yang perlu dikerjakan baik langsung maupun tidak langsung sejak sebelum memproduksi barang/jasa, proses produksi, menyampaikan hasil pekerjaan ke tangan konsumen dan layanan purna jual. Aktivitas pokok ini akan mendukung JTP dalam mewujudkan visi Menjadi kontraktor pemeliharaan jalan tol yang profesional, terpercaya, dan terkemuka; melalui penyelenggaraan proyek yang tepat mutu, tepat waktu, tepat biaya dan peduli keselamatan kerja serta lingkungan.

Aktivitas kedua atau aktivitas pendukung merupakan kegiatan-kegiatan penunjang terlaksananya aktivitas pokok agar terselenggara dengan baik, seperti diantaranya struktur organisasi pendukung, sumber daya manusia, teknologi, dan pengadaan. Aktivitas pendukung ini mendukung visi JTP melalui pengembangan profesionalisme (SDM \& Organisasi) dan pembentukan iklim kerja yang nyaman dan menghargai kontribusi serta membangun sistem manajemen pemeliharaan jalan tol untuk efektifitas pencapaian Standar Pelayanan Mutu (SPM) jalan tol perusahaan induk.

Aktivitas ketiga yaitu mencari sinergi yang potensial yang dapat ditemukan antara berbagai produk/jasa yang dihasilkan dengan usaha strategis yang dimiliki oleh JTP. Aktivitas ini akan mendukung visi JTP melalui upaya menjaga perusahaan tetap sehat dan menciptakan laba yang memadai untuk kelangsungan hidup dan pertumbuhan perusahaan.

Berdasarkan analisis rantai nilai diperoleh delapan kekuatan dan tujuh kelemahan yang dikompilasi dalam matriks IFE (Tabel 2). Nilai tertimbang dari matriks IE adalah 2,52 menunjukkan 
JTP masih memiliki kekuatan-kekuatan yang bisa dijadikan dasar pengembangan strategi, walau banyak kelemahan yang harus diatasi.

Tabel 2. Matrik IFE

\begin{tabular}{clccc}
\hline No & \multicolumn{1}{c}{ Kekuatan } & Bobot & Rating & Score \\
\hline 1 & Keleluasaan memilih rekanan supplier/subkontraktor & 0,04 & 4 & 0,15 \\
2 & Memiliki pengalaman termasuk sistem dan SOP pekerjaan pemeliharaan & 0,05 & 4 & 0,21 \\
3 & Pengecekan mutu hasil pekerjaan & 0,08 & 4 & 0,34 \\
4 & Kebijakan holding menetapkan sebagai asset maintainer di Jasa Marga & 0,07 & 3 & 0,22 \\
& Group & 0,05 & 3 & 0,17 \\
5 & Review Prosedur Quality Control Check (QCC) setiap tahun & 0,05 & 3 & 0,18 \\
6 & Struktur organisasi pendukung ditetapkan dengan jelas & 0,07 & 4 & 0,26 \\
7 & JMTM mengimplementasikan teknologi terkini pemeliharaan jalan & 0,05 & 3 & 0,16 \\
8 & Memiliki pokja yang melaksanakan pengadaan secara terpusat & Bobot & Rating & Score \\
\hline No & Kelemahan & 0,09 & 1 & 0,12 \\
\hline 1 & Pengendalian proyek belum sepenuhnya efisien & 0,09 & 2 & 0,18 \\
2 & Produk/Jasa yang disampaikan ke customer belum memenuhi spesifikasi & 0,09 & 2 & 0,13 \\
3 & Promosi dan harga penawaran kurang kompetitif & 0,08 & 1 & 0,11 \\
4 & Harga relatif premium dibanding kompetitor & 0,05 & 2 & 0,10 \\
5 & Kompetensi personil keuangan, marketing \& sales belum memenuhi & & & \\
& kebutuhan & 0,07 & 2 & 0,10 \\
6 & Keterbatasan anggaran untuk menerapkan teknologi terkini & 0,06 & 2 & 0,10 \\
\hline 7 & Pengadaan masih dilakukan secara manual & 1,00 & & 2,52 \\
\hline & TOTAL & & &
\end{tabular}

Sumber : David \& David (2016); hasil pengolahan penulis

Hasil evaluasi matriks internal menunjukan bahwa terdapat empat kekuatan terpenting yang miliki oleh JTP saat ini yaitu keleluasaan memilih rekanan subkontraktor, memiliki pengalaman termasuk sistem dan SOP pekerjaan pemeliharaan, pengecekan mutu hasil pekerjaan, serta telah mengimplementasikan teknologi terkini pemeliharaan jalan. Keempat kekuatan tersebut mendapatkan rating empat. Dari segi kepentingan, pengecekan mutu hasil pekerjaan menjadi kekuatan yang paling penting bagi perusahaan. Hal ini terlihat dari nilai bobot yang diperoleh, yaitu 0,08.

Dari segi kelemahan, perusahaan sangat lemah dalam dua aspek yaitu pengendalian proyek belum sepenuhnya efisien dan harga relatif premium dibanding kompetitor. Hal tersebut ditunjukan dengan nilai rating satu yang diperoleh. Sedangkan berdasarkan kepentingannya, kelemahan perusahaan yang harus segera diperbaiki yaitu pengendalian proyek belum sepenuhnya efisien, produk/jasa yang disampaikan ke pelanggan belum memenuhi spesifikasi, serta penurunan profitabilitas yang masing-masing memiliki bobot 0,09 .

\section{Pengembangan Alternatif Strategi}

Nilai tertimbang $\mathrm{EFE}=2,78$ dan IFE $=2,52$ kemudian dipetakan ke dalam matriks Internal Eksternal (IE) untuk mengetahui posisi dan strategi utama yang akan dijalankan oleh perusahaan. Gambar 2 menunjukkan bahwa JTP berada pada sel no 5 di dalam matriks IE atau sel dengan strategi hold and maintain. Seperti dikatakan David \& David (2016), perusahaan yang berada dalam sel hold and maintain sebaiknya mengambil strategi penetrasi pasar dan/atau pengembangan produk. 


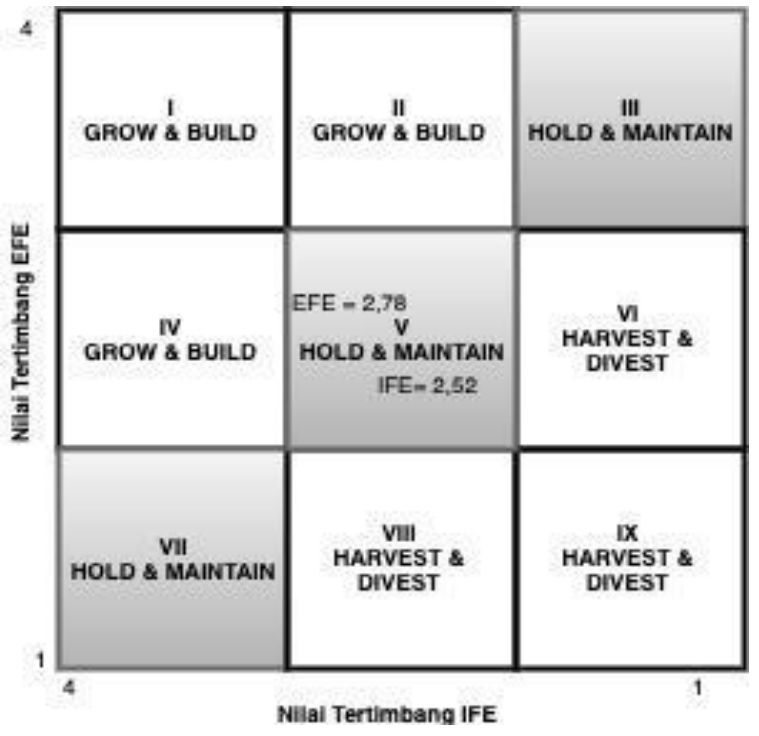

Gambar 2. Matriks IE JTP

Sumber: David \& David, 2016; hasil pengolahan penulis

Menurut David \& David (2016), walau perusahaan telah mengetahui bahwa strategi bisnis yang sebaiknya diambil adalah penetrasi pasar dan pengembangan produk, namun perusahaan perlu mendetilkan strategi tersebut dengan bantuan matriks TOWS. Berdasarkan hasil analisis SWOT terdapat satu alternatif strategi S-O yang dapat diimplementasikan yaitu mendapatkan pekerjaan pemeliharaan di seluruh ruas Jalan Tol Jasa Marga Group baik di ruas -ruas Jasa Marga eksisting maupun di ruas Anak Perusahaan Jalan Tol (APJT) serta jalan non Jasa Marga Group mulai tahap inspeksi, perencanaan program dan pelaksanaan pekerjaan pemeliharaan. Saat ini JTP telah mengerjakan pekerjaan pemeliharaan di seluruh ruas Cabang dan sebagian APJT di Jasa Marga Group sepanjang $903 \mathrm{Km}$ dan ditargetkan pekerjaan di seluruh APJT pun akan dikerjakan oleh JTP sehingga nantinya target jalan tol yang dipelihara mencapai $1500 \mathrm{Km}$. Strategi ini merupakan strategi besar yang melibatkan strategi lainnya dengan tahapan penerapan terdiri dari:

1. Melakukan inisiasi pekerjaan spesialis seperti diantaranya penghamparan aspal, rambu, marka dan grouting dilakukan secara swakelola oleh JTP.

2. Membangun pabrik-pabrik pengolahan material untuk pekerjaan spesialis yang dijalankan oleh JTP sendiri.

3. Mengoperasikan kembali seluruh peralatan untuk penghamparan aspal yang dimiliki oleh JTP.

4. Mengevaluasi produktifitas alat berat.

5. Memperbaiki strategi marketing untuk memperluas pangsa pasar pemeliharaan jalan tol di Jasa Marga Group maupun di luar Jasa Marga Group.

Berdasarkan hasil analisis SWOT terdapat satu alternatif strategi S-T yang dapat diimplementasikan yaitu penerapan Performance Based Maintenance Contract (PBMC) dengan kontrak jangka panjang menjadi strategi yang paling penting bagi JTP untuk dapat memaksimalkan setiap lini bisnisnya baik di bidang perencanaan, proyek, maupun unit pendukung. Penerapan PBMC 
ini juga diharapkan dapat memberikan pendapatan yang optimal bagi JTP karena dapat melaksanakan pekerjaan pemeliharaan secara swakelola dari hulu ke hilir serta mencegah idle-nya AMP, alat berat, maupun SDM pelaksana proyek pemeliharaan selama pelaksanaan pekerjaan pemeliharaan baik di ruasruas Jasa Marga eksisting maupun di ruas Anak Perusahaan Jalan Tol (APJT) serta jalan non Jasa Marga Group. Selain itu, melalui strategi penerapan PBMC diharapkan JTP akan memiliki peluang untuk unggul dibanding kompetitor-kompetitor lainnya dengan pertimbangan: Kompetitor belum mempersiapkan dengan baik penilaian kondisi aset, sehingga proposal penawaran pemeliharaan pemenuhan SPM memiliki nilai teknik yang rendah; Jangka waktu pelaksanaan PBMC selama lima tahun bertujuan agar kompetitor akan sulit mengikuti lelang selanjutnya karena membutuhkan biaya yang besar untuk meneliti kondisi aset apabila tidak terlibat secara langsung dalam penyusunan basis data; Kompetitor yang akan mengikuti lelang PBMC akan didominasi oleh Kontraktor BUMN Karya karena nilai paket pekerjaan yang besar, padahal di sisi lain Kontraktor Karya lebih memiliki keahlian di bidang pembangunan bukan pemeliharaan; dan Apabila JTP telah mendapatkan kontrak PBMC, peluang untuk menjadi market leader di industri pemeliharaan jalan tol dapat terwujud dengan menerapkan strategi keunggulan biaya untuk menguasai pasar mengingat biaya tetap sudah diakomodasi dalam kontrak PBMC.

Berdasarkan hasil analisis SWOT terdapat satu alternatif strategi W-O yang dapat diimplementasikan yaitu membangun kompetensi dan kapabilitas sebagai penyedia jasa perencana dan pelaksana pemeliharaan jalan tol. Hal ini juga akan mendukung strategi JTP dalam menerapkan pola PBMC di jalan tol. Kompetensi dan kapabilitas yang terbangun juga akan membantu JTP untuk mendapatkan posisi yang unggul dibanding kompetitor-kompetitornya.

Berdasarkan hasil analisis SWOT terdapat satu alternatif strategi W-T yang dapat diimplementasikan yaitu melakukan inovasi produk-produk pemeliharaan melalui kerja sama dengan lembaga penelitian dan perusahaan-perusahaan di luar negeri yang memiliki bisnis serupa dengan JTP untuk dijadikan benchmark, sehingga akan didapatkan produk yang lebih efektif dan efisien serta memiliki kualitas serta spesifikasi teknis yang ditetapkan oleh pelanggan. Strategi ini akan dikembangkan melalui: Kerja sama dengan Lembaga Penelitian (PUSJATAN maupun LAPI ITB) terkait inovasi cold mix (material penambal jalan secara cepat) dan pemanfaatan recycled asphalt (aspal daur ulang); Studi banding dengan West NEXCO terkait pengembangan Sistem Manajemen Pemeliharaan; Pemberian insentif (reward) kepada karyawan yang melakukan inovasi; Implementasi produk inovasi di dalam proses kerja yang memberikan manfaat kepada JTP secara keseluruhan.

\section{Penetapan Strategi Prioritas}

Bila dikaitkan dengan strategi utama sesuai dengan Pazouki, dkk. (2017), David \& David (2016), dan Abbasi, dkk. (2019) maka yang termasuk strategi penetrasi pasar adalah mendapatkan pekerjaan pemeliharaan di seluruh ruas jalan tol Jasa Marga Group dan Non Jasa Marga, sedangkan 
yang termasuk strategi pengembangan produk adalah penerapan Performance Based Maintenance Contract (PBMC) dengan kontrak jangka panjang dan melakukan inovasi produk-produk pemeliharaan.

Strategi mendapatkan pekerjaan pemeliharaan di seluruh ruas Jasa Marga Group dan Non Jasa Marga berasal dari kekuatan yang dimiliki oleh PT JTP yaitu keleluasaan memilih rekanan supplier/subkontraktor, memiliki pengalaman termasuk sistem dan SOP pekerjaan pemeliharaan, pengecekan mutu hasil pekerjaan, kebijakan perusahaan induk menetapkan sebagai asset maintainer di Jasa Marga Group, serta mengimplementasikan teknologi terkini pemeliharaan jalan

Sama halnya dengan strategi penerapan PBMC dengan kontrak jangka panjang yang juga berasal dari kekuatan dari JTP yaitu yaitu keleluasaan memilih rekanan supplier/subkontraktor, memiliki pengalaman termasuk sistem dan SOP pekerjaan pemeliharaan, pengecekan mutu hasil pekerjaan, review Prosedur Quality Control Check (QCC) setiap tahun, serta memiliki pokja yang melaksanakan pengadaan secara terpusat.

Adapun strategi membangun kompetensi dan kapabilitas sebagai penyedia jasa perencana dan pelaksana pemeliharaan jalan tol tidak dilakukan evaluasi lebih lanjut karena strategi ini dijadikan sebagai bagian dari aktifitas strategi mendapatkan pekerjaan pemeliharaan di seluruh ruas jalan tol Jasa Marga Group dan Non Jasa Marga serta penerapan PBMC dengan kontrak jangka panjang.

Penetapan strategi prioritas selanjutnya dilakukan dengan QSPM (Tabel 3).

Tabel 3. Quantitative Strategic Planning Matrix untuk JTP

\begin{tabular}{|c|c|c|c|c|c|c|c|}
\hline \multicolumn{8}{|c|}{10} \\
\hline & \multicolumn{3}{|c|}{1} & \multicolumn{2}{|c|}{2} & \multicolumn{2}{|c|}{3} \\
\hline & & \multicolumn{2}{|c|}{$\begin{array}{c}\text { Mendapatkan } \\
\text { pekerjaan } \\
\text { pemeliharaan di } \\
\text { seluruh ruas jalan tol } \\
\text { Jasa Marga Group \& } \\
\text { Non Jasa Marga }\end{array}$} & \multicolumn{2}{|c|}{$\begin{array}{c}\text { Penerapan } \\
\text { Performance Based } \\
\text { Maintenance } \\
\text { Contract (PBMC) } \\
\text { dengan kontrak } \\
\text { jangka panjang }\end{array}$} & \multicolumn{2}{|c|}{$\begin{array}{l}\text { Melakukan } \\
\text { inovasi produk- } \\
\text { produk } \\
\text { pemeliharaan }\end{array}$} \\
\hline Faktor-faktor Strategis & Bobot & $\mathbf{A S}$ & TAS & AS & TAS & AS & TAS \\
\hline Peluang & & & & & & & \\
\hline $\begin{array}{l}\text { Masifnya Target Pembangunan } \\
\text { Infrastruktur Jalan Tol hingga } \\
2024\end{array}$ & 0,04 & 3 & 0,114 & 3 & 0,114 & 1 & 0,038 \\
\hline $\begin{array}{l}\text { Proyeksi Pertumbuhan } \\
\text { Ekonomi Indonesia yang } \\
\text { Relatif Tinggi }\end{array}$ & 0,04 & 3 & 0,134 & 3 & 0,134 & 2 & 0,090 \\
\hline $\begin{array}{l}\text { Peningkatan Jumlah } \\
\text { Kendaraan Bermotor }\end{array}$ & 0,07 & 3 & 0,200 & 3 & 0,200 & 3 & 0,200 \\
\hline Pemeliharaan Preventif Jalan & 0,07 & 3 & 0,217 & 4 & 0,289 & 4 & 0,289 \\
\hline $\begin{array}{l}\text { Implementasi Green } \\
\text { Construction }\end{array}$ & 0,04 & 2 & 0,081 & 2 & 0,081 & 4 & 0,162 \\
\hline $\begin{array}{l}\text { Pemenuhan Regulasi Standar } \\
\text { Pelayanan Minimal Jalan Tol }\end{array}$ & 0,10 & 4 & 0,396 & 4 & 0,396 & 3 & 0,297 \\
\hline $\begin{array}{l}\text { Pelaksanaan Kontrak } \\
\text { Manajemen Pemeliharaan }\end{array}$ & 0,09 & 3 & 0,280 & 1 & 0,093 & 1 & 0,093 \\
\hline Menjalankan Etika Bisnis & 0,09 & 4 & 0,377 & 4 & 0,377 & 4 & 0,377 \\
\hline $\begin{array}{l}\text { Ancaman } \\
\text { Regulasi yang ketat terkait } \\
\text { Undang-Undang Jasa } \\
\text { Konstruksi }\end{array}$ & 0,06 & 3 & 0,179 & 4 & 0,239 & 1 & 0,060 \\
\hline
\end{tabular}


Febriano, R. \& Munir, N.S.. (2021). Formulasi Strategi Bisnis PT Jalan Tol Perkasa ....

\begin{tabular}{|c|c|c|c|c|c|c|c|}
\hline $\begin{array}{l}\text { Tuntutan Stakeholder yang } \\
\text { Tinggi cont: Pemerintah, } \\
\text { Pengguna Jalan Tol }\end{array}$ & 0,07 & 3 & 0,220 & 4 & 0,294 & 4 & 0,294 \\
\hline $\begin{array}{l}\text { Keterbatasan jumlah supplier } \\
\text { untuk produk/jasa pekerjaan } \\
\text { pemeliharaan yang bersifat } \\
\text { khusus dan spesifik }\end{array}$ & 0,04 & 2 & 0,088 & 3 & 0,132 & 4 & 0,176 \\
\hline $\begin{array}{l}\text { Kompetisi melalui tender yang } \\
\text { semakin ketat }\end{array}$ & 0,07 & 1 & 0,072 & 4 & 0,290 & 1 & 0,072 \\
\hline $\begin{array}{l}\text { Pesaing semakin banyak } \\
\text { karena industri pemeliharaan } \\
\text { jalan tol mudah diduplikasi } \\
\text { model bisnisnya }\end{array}$ & 0,08 & 2 & 0,150 & 3 & 0,225 & 3 & 0,225 \\
\hline $\begin{array}{l}\text { Produk-produk pengganti yang } \\
\text { dipatenkan oleh Kompetitor }\end{array}$ & 0,06 & 1 & 0,061 & 1 & 0,061 & 4 & 0,245 \\
\hline $\begin{array}{l}\text { Kompetitor menyediakan } \\
\text { layanan Kontrak Manajemen } \\
\text { Pemeliharaan lebih baik }\end{array}$ & 0,06 & 3 & 0,195 & 1 & 0,065 & 2 & 0,130 \\
\hline TOTAL & 1,00 & & & & & & \\
\hline \multicolumn{8}{|l|}{ Kekuatan } \\
\hline $\begin{array}{l}\text { Keleluasaan memilih rekanan } \\
\text { supplier/subkontraktor }\end{array}$ & 0,04 & 3 & 0,120 & 4 & 0,160 & 2 & 0,080 \\
\hline $\begin{array}{l}\text { Memiliki pengalaman } \\
\text { termasuk sistem dan SOP } \\
\text { pekerjaan pemeliharaan }\end{array}$ & 0,05 & 4 & 0,217 & 4 & 0,217 & 2 & 0,108 \\
\hline $\begin{array}{l}\text { Pengecekan mutu hasil } \\
\text { pekerjaan }\end{array}$ & 0,08 & 3 & 0,254 & 3 & 0,254 & 3 & 0,254 \\
\hline $\begin{array}{l}\text { Kebijakan holding menetapkan } \\
\text { sebagai asset maintainer di } \\
\text { Jasa Marga Group }\end{array}$ & 0,07 & 4 & 0,288 & 3 & 0,216 & 2 & 0,144 \\
\hline $\begin{array}{l}\text { Review Prosedur Quality } \\
\text { Control Check (QCC) setiap } \\
\text { tahun }\end{array}$ & 0,05 & 4 & 0,202 & 4 & 0,202 & 2 & 0,101 \\
\hline $\begin{array}{l}\text { Struktur organisasi pendukung } \\
\text { ditetapkan dengan jelas }\end{array}$ & 0,05 & 2 & 0,107 & 3 & 0,161 & 2 & 0,107 \\
\hline $\begin{array}{l}\text { JMTM mengimplementasikan } \\
\text { teknologi terkini pemeliharaan } \\
\text { jalan }\end{array}$ & 0,07 & 2 & 0,131 & 4 & 0,262 & 4 & 0,262 \\
\hline $\begin{array}{l}\text { Memiliki pokja yang } \\
\text { melaksanakan pengadaan } \\
\text { secara terpusat }\end{array}$ & 0,05 & 2 & 0,099 & 3 & 0,149 & 1 & 0,050 \\
\hline \multicolumn{8}{|l|}{ Kelemahan } \\
\hline $\begin{array}{l}\text { Pengendalian proyek belum } \\
\text { sepenuhnya efisien }\end{array}$ & 0,09 & 2 & 0,181 & 3 & 0,271 & 2 & 0,181 \\
\hline $\begin{array}{l}\text { Produk/Jasa yang disampaikan } \\
\text { ke customer belum memenuhi } \\
\text { spesifikasi }\end{array}$ & 0,09 & 3 & 0,265 & 4 & 0,353 & 3 & 0,265 \\
\hline $\begin{array}{l}\text { Promosi dan harga penawaran } \\
\text { kurang kompetitif }\end{array}$ & 0,09 & 3 & 0,268 & 3 & 0,268 & 3 & 0,268 \\
\hline $\begin{array}{l}\text { Harga relatif premium } \\
\text { dibanding kompetitor }\end{array}$ & 0,08 & 3 & 0,248 & 3 & 0,248 & 4 & 0,331 \\
\hline $\begin{array}{l}\text { Kompetensi personil } \\
\text { keuangan, marketing \& sales } \\
\text { belum memenuhi kebutuhan }\end{array}$ & 0,05 & 3 & 0,164 & 4 & 0,219 & 4 & 0,219 \\
\hline $\begin{array}{l}\text { Keterbatasan anggaran untuk } \\
\text { menerapkan teknologi terkini }\end{array}$ & 0,07 & 2 & 0,138 & 3 & 0,207 & 3 & 0,207 \\
\hline $\begin{array}{l}\text { Pengadaan masih dilakukan } \\
\text { secara manual }\end{array}$ & 0,06 & 2 & 0,111 & 2 & 0,111 & 1 & 0,055 \\
\hline TOTAL & 1,00 & & 5,559 & & 6,290 & & 5,381 \\
\hline
\end{tabular}


Berdasarkan Tabel 3 diperoleh hasil total nilai daya tarik tertinggi yang merupakan prioritas pertama dalam pemilihan strategi adalah penerapan PBMC dengan kontrak jangka panjang dengan nilai TAS 6,290. Selanjutnya strategi dengan total nilai daya tarik tertinggi kedua yaitu mendapatkan pekerjaan pemeliharaan di seluruh ruas jalan tol Jasa Marga Group \& Non Jasa Marga dengan nilai TAS 5,559. Nilai terendah diperoleh untuk strategi melakukan inovasi produk-produk pemeliharaan yang memiliki TAS 5,381.

\section{KESIMPULAN DAN SARAN}

Memuat kesimpulan yang diperoleh dari penelitian ini dan dilarang menampilkan statistik, menjelaskan implikasi temuan dan keterbatasan riset, serta jika perlu saran yang dikemukakan peneliti untuk riset yang akan datang. Berdasarkan hasil analisis yang telah dilakukan terhadap faktor eksternal dan internal PT JTP, diperoleh strategi utama PT JTP tahun 2020 s.d. 2022 berdasarkan matriks IE yaitu penetrasi pasar dan pengembangan produk.

Selanjutnya dengan bantuan Matriks SWOT diperoleh tiga alternatif strategi bisnis yang dapat dijalankan oleh PT JTP untuk dapat mencapai target pendapatan usaha dan profit yang sudah direncanakan yaitu:

1. Penerapan Performance Based Maintenance Contract (PBMC) dengan kontrak jangka panjang.

2. Mendapatkan pekerjaan pemeliharaan di seluruh ruas jalan tol Jasa Marga Group dan Non Jasa Marga.

3. Melakukan inovasi produk-produk pemeliharaan. 


\section{DAFTAR PUSTAKA}

Abbasi, F., Esparcia, J., \& Saadi, H. A. (2019). From analysis to formulation of strategies for farm advisory services: Valencia - Spain): An application through SWOT and QSPM matrix. European Countryside, 11(1), 43-73.

Collins, J.C., \& Porras, J.I. (2005). Built to last : successful habits of visionary companies 3rd edition. London : Random House Business

Coman, A., \& Ronen, B. (2009). Focused SWOT: Diagnosing critical strengths and weaknesses. International Journal of Production Research, 47(20), 5677

David, F., dan David, F. (2016). Strategic Management: A Competitive Approach, Concepts, and Cases 16th edition. New Jersey: Pearson

Denzin, N.K. \& Lincoln, Y.S. (2018). The Sage handbook of qualitative research 5th edition. Los Angeles : Sage

Gulati, R., Mikhail, O., Morgan, R. O., \& Sittig, D. F. (2016). Vision statement quality and organizational performance in U.S. hospitals. Journal of Healthcare Management, 61(5), 335351.

Helms, M. M., \& Nixon, J. (2010). Exploring SWOT analysis - where are we now?: A review of academic research from the last decade. Journal of Strategy and Management, 3(3), 215-251.

Karsaman, R. H., \& Weningtyas, W. (2015). Enhancing a better operation management of indonesian toll road. International Journal of Economics and Financial Issues, 5(1)

Pazouki, M., Jozi, S. A., \& Ziari, Y. A. (2017). Strategic management in urban environment using SWOT and QSPM model. Global Journal of Environmental Science and Management, 3(2), 207216

Serfointein, E., \& Govender, K. K. (2020). Stakeholders' views regarding macro-environment impacts on commercial flight operations in south africa. Journal of Transport and Supply Chain Management, 14

Singh, S., \& Srivastava, S. (2019). External factors affecting indian hand loom industry: A paradigm shift. International Journal of Business Insights and Transformation, 12(1), 33-41.

Slintak, K., \& Dvorsky, J. (2019). The purpose of firms and its influence on formulating their missions and visions. Montenegrin Journal of Economics, 15(2), 15-29.

Vlados, C. (2019). On a correlative and evolutionary SWOT analysis. Journal of Strategy and Management, 12(3), 347-363. 